\title{
Practical recommendations for the application of DE 59/2013
}

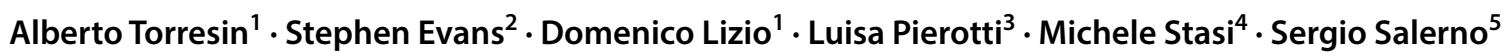

Received: 15 February 2019 / Accepted: 19 March 2019

(C) Italian Society of Medical Radiology 2019

\begin{abstract}
The changes introduced with Council Directive 2013/59/Euratom will require European Member States adapt their regulations, procedures and equipment to the new high standards of radiation safety. These new requirements will have an impact, in particular, on the radiology community (including medical physics experts) and on industry. Relevant changes include new definitions, a new dose limit for the eye lens, non-medical imaging exposures, procedures in asymptomatic individuals, the use and regular review of diagnostic reference levels (including interventional procedures), dosimetric information in imaging systems and its transfer to the examination report, new requirements on responsibilities, the registry and analysis of accidental or unintended exposure and population dose evaluation (based on age and gender distribution). Furthermore, the Directive emphasises the need for justification of medical exposure (including asymptomatic individuals), introduces requirements concerning patient information and strengthens those for recording and reporting doses from radiological procedures, the use of diagnostic reference levels, the availability of dose-indicating devices and the improved role and support of the medical physics experts in imaging.
\end{abstract}

Keywords BSS · European Directive Euratom · Medical exposures $\cdot$ Radiation protection $\cdot$ Radiodiagnostic and radiotherapeutic procedures

\section{Introduction}

The new European Directive 2013/59/Euratom [1], laying down basic safety standards (BSS) for protection against the dangers arising from exposure to ionising radiation and repealing Directives 89/618/Euratom, 90/641/Euratom, 96/29/Euratom, 97/43/Euratom and 2003/122/Euratom, is expected to have a relevant and positive impact on European radiodiagnostic and radiotherapeutic procedures.

\footnotetext{
Alberto Torresin

alberto.torresin@unimi.it

Stephen Evans

shevans58@gmail.com

Domenico Lizio

domenico.lizio@ospedaleniguarda.it

Luisa Pierotti

luisa.pierotti@gmail.com

Michele Stasi

mstasi@mauriziano.it

Sergio Salerno

sergio.salerno@unipa.it
}

The basic safety standards take into account the new recommendations of the International Commission on Radiological Protection (ICRP) [2,3] and are revised in the light of new scientific evidence and operational experience. The Directive was unanimously adopted by the Council of the European Union (EU) on 5 December 2013 after 4 years of work by different European scientific and technical committees. The Council meeting held in Brussels on 5 December 2013 highlighted that the new Directive, under which the Member States will establish legal requirements and an

1 Struttura Complessa di Fisica Sanitaria, ASST GOM Niguarda, p.zza dell'Ospedale Maggiore 3, 20162 Milan, Italy

2 Windsor, Berkshire, UK

3 Direzione Fisica Sanitaria, Azienda Ospedaliera Universitaria di Bologna, Policlinico S.Orsola Malpighi Via Pietro Albertoni, 15, 40138 Bologna, Italy

4 Azienda Ospedaliera Ordine Mauriziano di Torino, Corso Re Umberto, 109, 10128 Turin, Italy

5 Dipartimento di Biomedicina, Neuroscienze e Diagnostica Avanzata, Policlinico Università di Palermo, Via del Vespro 127, 90127 Palermo, Italy 
appropriate regime of regulatory control, reflects a system of radiation protection based on the principles of justification, optimisation and dose limitation for exposures to ionising radiations. Dose limits shall not apply to medical exposures.

According to the new Directive, a high level of competence and a clear definition of responsibilities and tasks among all professionals involved in medical exposures are fundamental to ensure adequate protection of patients undergoing medical radiodiagnostic and radiotherapeutic procedures. This applies to medical doctors, dentists and other health professionals entitled to take clinical responsibility for individual medical exposures, to medical physics experts and to other professionals carrying out practical aspects of medical radiological procedures, such as radiographers and technicians in radiodiagnostic medicine, nuclear medicine and radiotherapy.

Furthermore, the Directive requires radiation protection education, training and provision of information.

The Directive distinguishes between existing, planned and emergency exposure situations. Considering this new framework, the Directive covers all exposure situations and all categories of exposure, namely occupational, public and medical.

The most relevant changes in the new Directive in comparison with the existing ones-96/29/Euratom [4] on the protection of workers and the general public and 97/43/ Euratom [5-7] on medical exposures-are:

1. New set of definitions (Article 4)

2. New dose limit for the lens of the eyes (Article 9)

3. Consideration of occupational doses in justification (Article 19) and optimisation (Article 32)

4. Regulations for radiological procedures involving asymptomatic individuals (Article 55)

5. Use and regular review of diagnostic reference levels (including interventional procedures) (Articles 56 and 58)

6. Education and training (Article 59)

7. Responsibilities (Article 57)

8. Role of medical physics experts in diagnostic and interventional procedures (Article 58)

9. New requirements for medical radiological equipment (Article 60)

10. Procedures: optimisation process, clinical protocols and clinical audit (Article 58)

11. Registry and analysis of accidental or unintended exposures (Article 63)

12. Population dose evaluation considering age distribution and gender (Article 64)

13. New "non-medical imaging exposures" (Article 22) replacing the old "medico-legal" exposures

Other requirements of Directive 2013/59/Euratom with high relevance to medical imaging are:
1. Dose constraints for occupational, public and medical exposure (Article 6)

2. Dose limits for occupational exposure including the new limit for the lens of the eyes of $20 \mathrm{mSv}$ in a single year (Article 9)

3. Pregnant worker protection (Article 10)

4. Education, information and training in the field of medical exposure (Article 18)

5. Chapter VI on occupational exposures, in particular:

- Operational protection of exposed workers (Article 32)

- Operational protection of apprentices and students (Article 33)

- Consultations with radiation protection experts (Article 34)

- Controlled and supervised areas (Articles 37-38)

- Radiological surveillance of the workplace (Article 39)

- Categorisation of exposed workers (Article 40)

- Individual monitoring and access to the results (Articles 41 and 44)

- Medical surveillance of exposed workers (Article 45)

\section{Main articles of 2013/59/Euratom appropriate to medical exposures}

Definitions For the purpose of the Directive, the following definitions shall apply:

“(49) "medical physics expert" means an individual or, if provided for in national legislation, a group of individuals, having the knowledge, training and experience to act or give advice on matters relating to radiation physics applied to medical exposure, whose competence in this respect is recognised by the competent authority;

(50) "medical radiological" means pertaining to radiodiagnostic and radiotherapeutic procedures, and interventional radiology or other medical uses of ionising radiation for planning, guiding and verification purposes"

Medical physics experts and medical radiological professionals are the health care personnel responsible for the practical application of the Directive within their specific competence; they provide fundamental support for the legal obligations for their hospitals. 


\section{Consideration of occupational doses in justification and optimisation}

Articles 55 and 56 in Chapter VII on Medical Exposures contain most of the requirements of the previous 97/43/ Euratom Directive on justification and optimisation, but the explicit consideration of occupational doses in justification and optimisation in some previous articles should be noted.

Article 19.4. Practices involving medical exposure shall be justified both as a class or type of practice, taking into account medical and, where relevant, associated occupational and public exposures, and at the level of each individual medical exposure.

Article 32.b. Member States shall ensure that the operational protection of exposed workers is based on optimisation of radiation protection in all working conditions, including occupational exposures as a consequence of practices involving medical exposures.

\section{Regulation for radiological procedures in asymptomatic individuals}

A new article (55.2.h) on justification has been added, concerning medical radiological procedures on asymptomatic individuals, to be performed for early disease detection. Such procedures should either be part of a health screening programme or require specific documented justification for that individual by the practitioner, in consultation with the referrer, following guidelines from relevant medical scientific societies and the competent authority. Special attention shall be given to the provision of information to the individual subject to medical exposure.

\section{Use and regular review of diagnostic reference levels (including interventional)}

The new Directive strengthens and expands the previous requirements regarding diagnostic reference levels.

Article 56.2. Member States shall ensure the establishment, regular review and use of diagnostic reference levels for radiodiagnostic examinations, having regard to the recommended European diagnostic reference levels where available, and where appropriate, for interventional radiology procedures and the availability of guidance for this purpose.

Article 58.f. underlines the need for appropriate local reviews whenever diagnostic reference levels are consistently exceeded and requires that appropriate corrective action is taken without undue delay.

\section{Education, information and training in the field of medical exposure}

Article 18 of the new Directive deals with education, information and training in the field of medical exposure. This article is referred to in Chapter VII (Medical Exposures) (Article 59), and its content is the same as in the previous 97/43/Euratom Directive.

Member States shall ensure that practitioners and the individuals involved in the practical aspects of medical radiological procedures have adequate education, information and theoretical and practical training for the purpose of medical radiological practices, as well as relevant competence in radiation protection.

For this purpose, Member States shall ensure that appropriate curricula are established and shall recognise the corresponding diplomas, certificates or formal qualifications.

Individuals undergoing relevant training programmes may participate in practical aspects of medical radiological procedures.

Member States shall ensure that continuing education and training after qualification are provided and, in the special case of the clinical use of new techniques, training is provided on these techniques and the relevant radiation protection requirements.

Member States shall encourage the introduction of a course on radiation protection in the basic curriculum of medical and dental schools.

\section{Responsibilities: Article 57}

Specific attention and adequate training must be provided to support communication to the patients of the benefits and risks associated with the radiation dose due to medical exposures, and similar information together with relevant guidance shall be provided to carers and comforters of patients who are not self-sufficient.

It is considered important that the "effective dose" quantity, as indicated by ICRP 103, is used only for the comparison of the risk among different practices; this metric should not be used to evaluate the risk to the individual patient.

It is recommended that information on the exposure to ionising radiations is integrated into the document for the acquisition of informed consent for the diagnostic or therapeutic procedure for procedures involving high exposure doses (computed tomography, interventional radiology, nuclear medicine and radiotherapy).

These informative aspects for the patient require adequate training of the radiological or radiotherapeutic specialist, and adequate time must be provided to ensure effective communication with the patient to acquire considered consent. 


\section{Procedures: Article 58}

It should be noted that the recording of the exposure parameters provided by the equipment (Article 58.b) is separate from the information that forms part of the referral guidelines (Article 58.c). This information should be contained in the clinical report or in the report of the medical specialists who use medical radiological equipment.

The information to be recorded in the medical radiological procedure [8] should be congruent with the metric used to describe the patient's exposure in relation to the technique and the medical radiological equipment used (Table 1).

Exposure information must appear in all referral guidelines and be made available to the referrer (Article 60.c). The data to be reported in the referral guidelines should take into account the indications in the guidelines of the relevant scientific societies of the different countries. Information relating to patient exposure should be expressed by the range of values of the metric used to describe the patient's exposure related to the clinical request. The range describes the variation between a minimum and a maximum related to a good radiological technique (e.g. min/max DLP (mGy.cm) or min/max KAP (mGy.cm²)).

Guidelines should provide the range of exposure values for the most common clinical modalities and indications; medical physics experts should identify, in collaboration with the radiological professional for that area, the appropriate exposure values to be selected, correlated with the relative and specific units of measurement.

The radiological report and, in complementary activity the clinical report, the exposure data of the specific examination should be stored in the hospital computer system for, as a minimum, high-dose diagnostic activities (e.g. computed radiography, interventional radiology activity, hybrid technologies) and for paediatric procedures.

The exposure data, linked to the medical procedure performed, becomes an element of the documentation that must be stored electronically and managed with the stored images and reports.

The time necessary to provide the dosimetric and risk information, especially for the high-dose procedures (interventional radiology, computed radiography, hybrid investigations), should be recognised and valued as the working activity of the medical physics expert and other radiological specialists involved in these tasks.

It would also be appropriate to provide a specific item and code in the nomenclator of the specialist services related to the evaluation and communication of the exposure data.

Since one of the objectives of the Directive (Article 64) is the estimate of the distribution of dose to the population from radiodiagnostic and interventional radiology procedures, the exposure data must be made available to regional central depositories and not only provided in reports.

For radiological practices for which a specific report is not issued (e.g. mammography screening, use of imaging in complementary radiological practices, such as haemodynamics, dentistry.), the specialist doctor, in collaboration with the medical physics expert and with the radiological manager, is responsible for defining and documenting the patient's exposure.

For complementary activities, the exposure data related to the imaging employed must be contained in the compulsory clinical report or in the operative report and, as a priority, in the hospital RIS-PACS systems that guarantee the correct keeping of data.

It will be necessary to implement RIS-PACS systems or other IT systems (e.g. surgical registries) with the option to transfer information on the exposure of the various procedures in radiological reports or, in complementary activity, in the clinical report.

A similar need arises for the registration and archiving of the exposure data of the procedures carried out in complementary activities.
Table 1 Exposure metric in relation to the technique and the medical radiological equipment used

\begin{tabular}{|c|c|}
\hline Image & Exposure metric \\
\hline Computed tomography & $\begin{array}{l}\text { Computed tomography dose index-CTDI vol }[\mathrm{mGy}] \text { and } \\
\text { Dose-Length Product-DLP }[\mathrm{mGy} \mathrm{cm}]\end{array}$ \\
\hline Interventional radiology and fluoroscopy & $\begin{array}{l}\text { Air Kerma-Area product KAP }\left[\mathrm{Gy} \mathrm{cm}^{2}\right] \text { and } \\
\text { Reference Air Kerma[mGy] }\end{array}$ \\
\hline Conventional radiology & $\begin{array}{l}\text { Air Kerma-Area product KAP }\left[\mathrm{mGy} \mathrm{cm}^{2} \text { or } \mu \mathrm{Gy} \mathrm{m}^{2}\right] \text {, or } \\
\text { DAP }\left[\mathrm{mGy} \mathrm{cm}^{2} \text { or } \mu \mathrm{Gy} \mathrm{m}^{2}\right] \text { and } \\
\text { Entrance Surface Air Kerma-ESAK }[\mathrm{mGy}]\end{array}$ \\
\hline $\mathrm{CBCT}$ & $\begin{array}{l}\text { Air Kerma-Area product KAP }\left[\mathrm{mGy} \mathrm{cm}^{2} \text { or } \mu \mathrm{Gy} \mathrm{m}^{2}\right] \text {, or } \\
\text { DAP }\left[\mathrm{mGy} \mathrm{cm} \text { or } \mu \mathrm{Gy} \mathrm{m}^{2}\right]\end{array}$ \\
\hline Mammography & Entrance Surface Air Kerma_ESAK [mGy], \\
\hline Nuclear medicine & Activity $[\mathrm{MBq}]$ and radiopharmaceutical \\
\hline $\begin{array}{l}\text { Radiotherapy (external beams) and sealed } \\
\text { sources }\end{array}$ & Dose to target and to critical organs [Gy] \\
\hline
\end{tabular}


Exposure monitoring systems (e.g. RDIM-Radiation Dose Index Monitoring, Dose Tracking or Dose Monitoring systems) are useful for monitoring patient exposures and helping with optimisation processes of radiological procedures. Their use is desirable, but not essential, for the achievement of the objectives of the Directive, and any use of such systems must be validated and certified by medical physics experts.

\section{Role of the medical physics expert in imaging}

Article 58 (procedures), part d, indicates that a medical physics expert shall be involved in radiodiagnostic and interventional radiology practices involving high doses as referred to in point (c) of Article 61(1) (i.e. interventional radiology and computed tomography). For other medical radiological practices, a medical physics expert shall be involved as appropriate, depending on the radiological risk posed by the practice, for consultation and advice.

Article 83 defines the responsibilities of the medical physics expert: Member States shall require the medical physics expert to act or give specialist advice as appropriate on matters relating to radiation physics for implementing the requirements set out in Chapter VII and in point (c) of Article 22(4) of the Directive (i.e. "Practices involving the deliberate exposure of humans for non-medical imaging purposes").

Member States shall ensure that, depending on the medical radiological practice, the medical physics expert takes responsibility for dosimetry, including physical measurements for evaluation of the dose delivered to the patient and other individuals subject to medical exposure, gives advice on medical radiological equipment and contributes in particular to the following:

a. Optimisation of the radiation protection of patients and other individuals subject to medical exposure, including the application and use of diagnostic reference levels;

b. The definition and performance of quality assurance of the medical radiological equipment;

c. Acceptance testing of medical radiological equipment;

d. The preparation of technical specifications for medical radiological equipment and installation design;

e. The surveillance of the medical radiological installations;

f. The analysis of events involving, or potentially involving, accidental or unintended medical exposures;

g. The selection of equipment required to perform radiation protection measurements; h. The training of practitioners and other staff in relevant aspects of radiation protection;

It is also required that the medical physics expert shall, where appropriate, liaise with the radiation protection expert.

\section{Equipment: Article 60}

Equipment for interventional radiology installed after 6 February 2018 must have a device to inform the practitioner and those carrying out practical aspects of the medical procedures of the quantity of radiation produced during the procedure.

Equipment for interventional radiology and computer radiography must have a device to inform the practitioner and those carrying out practical aspects of the medical procedures of the quantity of radiation produced at the end of the procedure. Such equipment installed after 6 February 2018 must be able to transfer the information required above to the record of the examination.

All new medical radiodiagnostic equipment must provide the practitioner with the relevant parameters for assessing patient dose and where appropriate to transfer this information to the record of the examination and, if available, to the RDIM systems to ensure data recording as required by the Directive for the purpose of dose assessment to the population.

Equipment used for external beam radiotherapy, installed after 6 February 2018, with energies greater than $1 \mathrm{MV}$, must have a device that verifies the key treatment parameters.

It is the responsibility of each department of radiology, nuclear medicine and radiotherapy to ensure the correct management, verification and safe storage of exposure data for the different procedures according to international standards using the reference metrics indicated in Table 1.

These parameters provide information on the individual procedure, but must take into account the level of uncertainty of the data supplied or estimated. Typically, the uncertainty will be $\pm 20-50 \%$ for radiological diagnostic and nuclear medical investigations; the uncertainties related to radiotherapy procedures will be significantly less. The uncertainty should be estimated by the appropriate medical physics expert for each modality.

It should be noted that the registration of the exposure data must be provided for all procedures, such as interventional radiology procedures performed with portable or remote equipment.

The exposure data, supplied by the medical radiological equipment outside radiology departments, must be managed as an integral part of the radiology information systems with 
the metrics indicated by the international standards and by the present document.

For radiotherapy treatments, the dose to the tumour target and to the critical organs is an integral part of the end-oftreatment clinical report. Exposure data deriving from the imaging used for the preparation of the treatment plan and verification must be recorded and archived according to the same procedures envisaged for diagnostic imaging.

For radiometabolic therapy treatments in nuclear medicine, reference should be made to the specific document/ guidelines that defines the specific fields of application for the different therapies/isotopes, provided by the manufacturer and as developed jointly by the Nuclear Medicine and Medical Physics societies.

For nuclear medicine activities, that use unsealed sources, the activity administered, the radiopharmaceutical used and correction factors that allow these data to be correlated with the patient's exposure must be documented.

For hybrid equipment, e.g. PET/CT, exposure data for both diagnostic techniques must be reported.

In order to guarantee the efficacy of the registration of the activity and the type of radioisotope used for nuclear medicine investigations, it is necessary, in compliance with the regulations for the good preparation of radiopharmaceuticals, that the flow of information throughout the process is also traceable and certified.

The exposure data will have to be managed by carrying out appropriate tests as indicated by current standards. It is recommended, if available, to use the information in the Radiation Dose Structured Report (RDSR). This must be implemented correctly and exhaustively by the equipment manufacturers and be updated throughout the life of the equipment used.

\section{Accidental and unintended exposures: Article 63}

Member States shall ensure that:

a. all reasonable measures are taken to minimise the probability and magnitude of accidental or unintended exposures of individuals subject to medical exposure;

b. for radiotherapeutic practices, the quality assurance programme includes a study of the risk of accidental or unintended exposures;

c. for all medical exposures, the undertaking implements an appropriate system for the record keeping and analysis of events involving or potentially involving accidental or unintended medical exposures, commensurate with the radiological risk posed by the practice;

d. arrangements are made to inform the referrer and the practitioner, and the patient, or their representative, about clinically significant unintended or accidental exposures and the results of the analysis; e. (i) the undertaking declares as soon as possible to the competent authority the occurrence of significant events as defined by the competent authority;

(ii) the results of the investigation and the corrective measures to avoid such events are reported to the competent authority within the time period specified by the Member State;

f. mechanisms are in place for the timely dissemination of information, relevant to radiation protection in medical exposure, regarding lessons learned from significant events.

Article 63 introduces a new set of requirements for registration and analysis of accidental and unintended medical exposures.

In the registration of accidental exposures, tools of "incident reporting" must be present to record and manage the incidents.

\section{Estimates of population doses: Article 64}

The age and gender must now be taken into account in the distribution of individual dose estimates from medical exposures. The competent authorities of each Member State will have responsibility for the registration and monitoring of population exposures; for this purpose, exposure data storage systems (RIS-PACS) become indispensable. RDIM systems are useful for transferring correct and certified data to central depositories responsible for collecting and analysing the data.

For such transfers, it is essential to use recognised international standards and precisely the IHE profiles for Radiation Exposure Monitoring (REM).

The data to be sent to the central depositories must be certified by the practitioner responsible for the radiological system and by the medical physics expert in order to ensure the correct management of exposure data.

The above-mentioned professionals must be provided with the appropriate instruments and technological resources to carry out their functions.

\section{General recommendation}

It is inappropriate to use the estimated effective dose parameter for an individual patient. This quantity refers to a standard patient (usually reference phantom) and should therefore not be used to derive individual radiological risk values (ICRP 103).

The evaluation of the radiation dose to the patient, if required or necessary, requires complex evaluation of the 
experimental data, and it is the exclusive competence of the medical physics expert.

If the referrer wants to know the risk associated with the estimate of the radiation dose absorbed by a patient, it should be obtained from the practitioner. The estimate of the absorbed dose is the responsibility of the medical physics expert who will carry out a personalised dosimetric evaluation.

Finally, it is considered essential that authoritative sources of information are used on the complex issue of medical exposures. The websites of the national scientific societies and international (www.eanm.org, www.efomp.org, www.estro.org, www.myesr.org, www.iaea.org, www.euros afeimaging.org and others) provide valid certifiable information compared to the often generic and unfounded information present on some other internet sites.

\section{Compliance with ethical standards}

Conflict of interest The authors declare that they have no conflict of interest.

Ethical standards This article does not contain any studies with human participants or animals performed by any of the authors.

\section{References}

1. EC (2013) COUNCIL DIRECTIVE 2013/59/EURATOM of 5 December 2013 laying down basic safety standards for protection against the dangers arising from exposure to ionising radiation, and repealing Directives 89/618/Euratom, 90/641/Euratom, 96/29/ Euratom, 97/43/Euratom and 2003/122/Euratom

2. International Commission on Radiological Protection (2007) ICRP Publication 103. The recommendations of the international commission on radiological protection. Ann ICRP 37(2-4):1-332

3. International Commission on Radiological Protection (2012) ICRP statement on tissue reactions and early and late effects of radiation in normal tissues and organs-threshold doses for tissue reactions in a radiation protection context. ICRP publication 118 . Ann ICRP 41(1-2):1-322

4. European Council Directive 96/29/Euratom laying down basic safety standards for the protection of the health of workers and the general public against the dangers arising from ionizing radiation. (1996) OJ of the EU. L 159; 1-114

5. European Council Directive 97/43/Euratom on health protection of individuals against the dangers of ionizing radiation in relation to medical exposure and repealing Directive 84/466/Euratom. (1997) OJ of the EU. L 180; 22-27

6. EC (2014) RP174 European guidelines on the medical physics expert

7. Summary of the European Directive 2013/59/Euratom: essentials for health professionals in radiology-European Society of Radiology (ESR) - Insights Imaging 6:411-417

8. Salerno S, Nardi C, Tudisca C et al (2018) Complete written/ oral information about dose exposure in CT: is it really useful to guarantee the patients' awareness about radiation risks? Radiol Med 123(10):788-798

Publisher's Note Springer Nature remains neutral with regard to jurisdictional claims in published maps and institutional affiliations. 